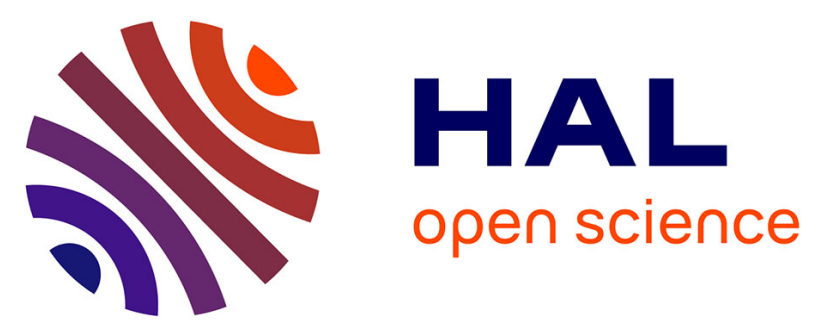

\title{
Integration of ring nanoelectrodes into microwell for the bioelectrochemical analysis in sub-picoliter volumes
}

Fadhila Sekli-Belaidi, William Tiddi, Matthieu Polverel, Gabriel Lemercier, Aurélie Lecestre, Pascal Dubreuil, Jérôme Launay, Pierre Temple-Boyer

\section{- To cite this version:}

Fadhila Sekli-Belaidi, William Tiddi, Matthieu Polverel, Gabriel Lemercier, Aurélie Lecestre, et al.. Integration of ring nanoelectrodes into microwell for the bioelectrochemical analysis in subpicoliter volumes. 18th International Conference on Solid-State Sensors, Actuators and Microsystems (TRANSDUCERS 2015), Jun 2015, Anchorage, AK, United States. 4p., 10.1109/TRANSDUCERS.2015.7181224 . hal-01874765

\section{HAL Id: hal-01874765 \\ https://hal.laas.fr/hal-01874765}

Submitted on 14 Sep 2018

HAL is a multi-disciplinary open access archive for the deposit and dissemination of scientific research documents, whether they are published or not. The documents may come from teaching and research institutions in France or abroad, or from public or private research centers.
L'archive ouverte pluridisciplinaire HAL, est destinée au dépôt et à la diffusion de documents scientifiques de niveau recherche, publiés ou non, émanant des établissements d'enseignement et de recherche français ou étrangers, des laboratoires publics ou privés. 


\title{
INTEGRATION OF RING NANOELECTRODES INTO MICROWELL FOR THE BIOELECTROCHEMICAL ANALYSIS IN SUB-PICOLITER VOLUMES
}

\author{
F. Sekli Belaïdi ${ }^{1,2}, W$. Tiddi ${ }^{1,2}$, M. Polverel $^{1,2}$, G. Lemercier $^{1,2,}$, \\ A. Lecestre ${ }^{1,2}$, P. Dubreuil ${ }^{1,2}$, J. Launay ${ }^{1,2}$ and P. Temple-Boyer ${ }^{1,2}$ \\ ${ }^{1}$ LAAS-CNRS; 7 avenue du colonel Roche, F-31400 Toulouse, France \\ and ${ }^{2}$ Université de Toulouse; UPS; LAAS; F-31400 Toulouse, France
}

\begin{abstract}
We report here the fabrication and the electrochemical characterization of recessed ring nanoelectrodes (RNE) integrated in microwell arrays. Such configuration has all advantages of microelectrodes arrays but is more suitable for electrochemical analysis in sub-picoliter volumes. The technological process based on the reactive ion etching of a $\mathrm{SiO}_{2} / \mathrm{Ti} / \mathrm{Pt} / \mathrm{Ti} / \mathrm{SiO}_{2}$ stacking is optimized in order to develop for the first time functional electrochemical microdevices on glass substrate. Electrochemical characterizations are finally conducted in order to study the amperometric behavior of recessed ring nanoelectrodes and to define design rules for optimizing the electrochemical detection properties of RNEbased microwell arrays. Finally, a "generation - collection mode" approach is proposed to define the effective collection factor of RNE into microwell. All these results demonstrate that recessed ring nanoelectrode arrays are fitted to the statistic analysis of single cells and to the detection of electrochemical species at the nanoscale.
\end{abstract}

\section{KEYWORDS}

Recessed ring nanoelectrode, microwell array, electrochemical characterization, sub-picoliter analysis

\section{INTRODUCTION}

The adaptation of electrochemical detection principles

to single cell analysis required the development of ultramicroelectrodes (UME). This was achieved thanks to glass-capillary UME [1]. Nevertheless, such technology was limited in terms of fabrication time, yield and reproducibility. So, microtechnologies were proposed for the integration of planar microelectrodes into micropit [2]. However, such microdevices are not fully adapted to the single cell analysis since electrical contact between cell and microelectrode can be responsible for cellular disturbances and hemispherical out-diffusion phenomena can prevent exocytosis monitoring. In order to tackle off this obstacle, ring micro/nanoelectrodes can be integrated into micro/nanocavities [3,4]. Nevertheless, up to now, such technologies were not adapted to single cell analysis due to too high or too small dimensions. In this work, we combine the advantages of nanotechnology with those of reactive etching to fabricate recessed ring nanoelectrodes (RNE) into microwell arrays to precisely trap single cells. We present the microfabrication, characterization, modeling/ simulation and application of this system to the analysis of single cell.

\section{EXPERIMENTAL SECTION}

Technological microfabrication

The integration of platinum-based, ring nanoelectrodes (RNE) into microwells was achieved using silicon technologies. Starting from a B33 glass substrate, an initial facultative step consisted in the deposition of a titanium/platinum/titanium (Ti/Pt/Ti, see hereafter) staking patterned using "lift off" technique. This allowed the fabrication of recessed disk microelectrodes (DME) at the microwell bottom if required (see hereafter). Then, the main technological process involved three deposition processes performed in a row. First, a $2.5 \mu \mathrm{m}$ silicon oxide $\left(\mathrm{SiO}_{2}\right)$ layer was deposited by plasma-enhanced chemical vapor deposition (PECVD). Indeed, compared to polymer-based layers [3], $\mathrm{SiO}_{2}$ provides higher dielectric properties, lower electrochemical activities and higher biocompatibility. Then, a $200 \mathrm{~nm}$ platinum layer was deposited by evaporation while using two $20 \mathrm{~nm}$ titanium interfacial layers to ensure platinum adhesion on $\mathrm{SiO}_{2}$, and another $2.5 \mu \mathrm{m}$ PECVD silicon oxide layer was deposited to form a $\mathrm{SiO}_{2} / \mathrm{Ti} / \mathrm{Pt} / \mathrm{Ti} / \mathrm{SiO}_{2}$ stacking. Finally, using a patterned photoresist mask, inductively coupled plasma reactive ion etching (ICP-RIE) was optimized thanks to three different gaseous mixtures, $\mathrm{CF}_{4} / \mathrm{Ar}, \mathrm{SF}_{6}$ and $\mathrm{Cl}_{2}$, in order to etch the whole stacking and to fabricate microwells (diameter: $\sim 6$ $\mu \mathrm{m}$, depth: $\sim 5.2 \mu \mathrm{m}$ ) with integrated, platinum-based, ring nanoelectrodes (Fig. 1). At least, a last photolithography / $\mathrm{CF}_{4} / \mathrm{Ar}$ etch step was performed in order to contact electrically the different nanoelectrodes and to realize functional electrochemical microdevices on glass substrate (Fig. 2 and 3).

\section{Electrochemical apparatus}

Electrochemical characterization was performed thanks to a three-electrode system using a silver $(\mathrm{Ag})$ wire as pseudo-reference electrode and a platinum $(\mathrm{Pt})$ wire as a counter electrode. Cyclic voltammetry and chronoamperometry experiments were performed in methanol ferrocene $(\mathrm{FcMeOH}, 1 \mathrm{mM})$ and potassium chloride $(\mathrm{KCl}$, $0.1 \mathrm{M}$ ) aqueous solutions deaerated with pure nitrogen. For each experiment, a $100 \mu 1$ drop of solution was placed on the studied device using an Eppendorf micropipette. The potentiostat used was a PARSTAT MC (Princeton Applied research) interfaced to a computer, using the VersaStudio software. In all experiments, a low-current amplifier and a Faraday cage was used. 


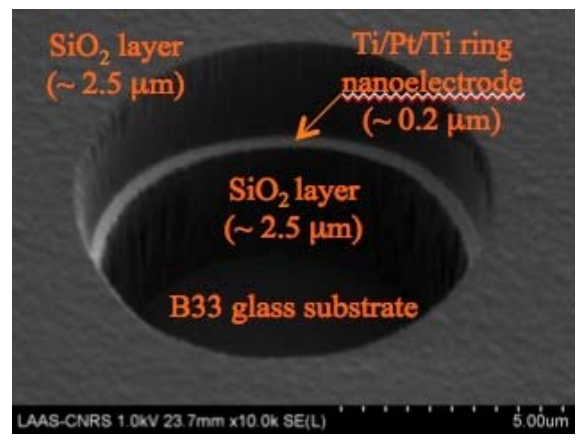

Figure 1: SEM image of $\mathrm{SiO}_{2}$-based microwell (radius: $\sim 3$ $\mu \mathrm{m}$, depth: $\sim 5.2 \mu \mathrm{m})$ with integrated, platinum-based, ring nanoelectrode (thickness: $0.2 \mu \mathrm{m}$ ) on B33 glass substrate

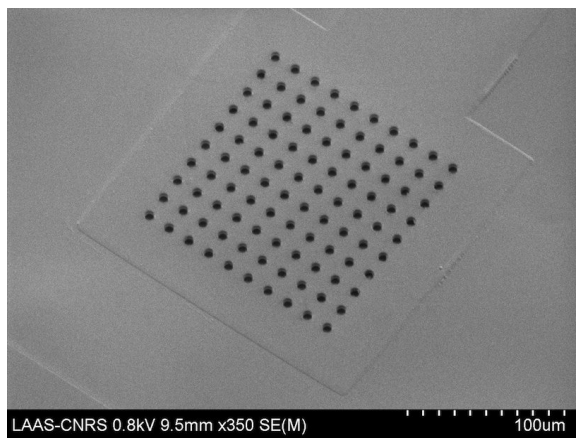

Figure 2: Microfabrication on B33 glass substrate of $10 \times 10$ microwell arrays with integrated, platinum-based, ring nanoelectrodes

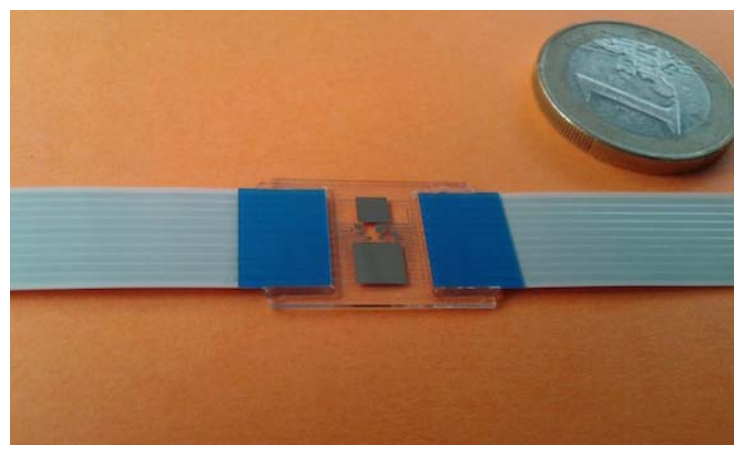

Figure 3: Realization on B33 glass substrate of functional electrochemical microdevices based on microwell arrays $(1 \times 1,10 \times 10$ and $100 \times 100)$ with integrated, platinum-based, ring nanoelectrodes

\section{RESULTS AND DISCUSSION}

\section{Recessed ring nanoelectrode realization}

If chemistries of $\mathrm{CF}_{4} / \mathrm{Ar}$ and $\mathrm{Cl}_{2}$ gases were widely known for etching silicon oxide $\left(\mathrm{SiO}_{2}\right)$ and platinum $(\mathrm{Pt})$ layers, an $\mathrm{SF}_{6}$ etching step was introduced to solve problems of high roughness at the bottom of the well $(0.1-2 \mu \mathrm{m})$. Indeed, during the $\mathrm{CF}_{4} / \mathrm{Ar}$ initial etching process, the $\mathrm{SiO}_{2}$ - based walls were attacked and therefore released oxygen species in the gaseous phase promoting the formation of titanium oxides $\left(\mathrm{TiO}_{\mathrm{x}}\right)$. The presence of these oxides were responsible for local differences of etching rates during the following $\mathrm{Cl}_{2}$ and $\mathrm{CF}_{4} / \mathrm{Ar}$ etching processes, and finally for micromasking phenomena. The $\mathrm{SF}_{6}$ breakthrough was therefore added to remove the thin titanium oxides present on the platinum layer before and after its etch [5].

Furthermore, even if ICP-RIE process should be anisotropic, the second $\mathrm{CF}_{4} / \mathrm{Ar}$ etching process was found to be responsible for a further etch of the upper silicon oxide $\mathrm{SiO}_{2}$ layer. The associated over-etching coefficient was estimated around 0.2 , leading to the formation of a $\sim 500 \mathrm{~nm}$ wide step at its mid-depth, and to the final realization of recessed ring nanoelectrodes (Fig. 4).

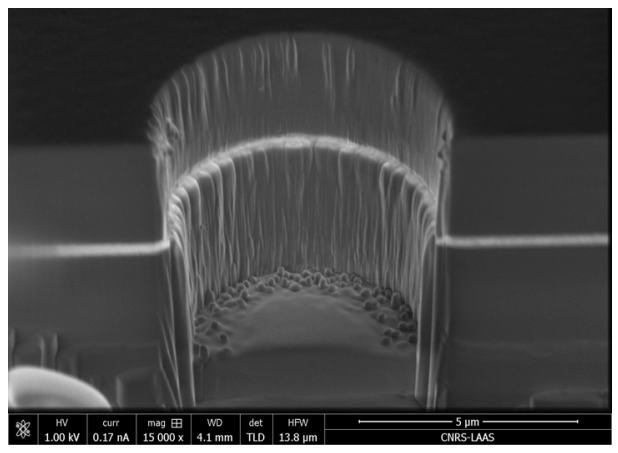

Figure 4: SEM image of a recessed ring nanoelectrode (inner radius: $\sim 3 \mu \mathrm{m}$, outer radius: $3.5 \mu \mathrm{m}$ ) integrated into a $\mathrm{SiO}_{2}$-made microwell

\section{Recessed ring nanoelectrode voltammetry}

These devices were finally characterized by cyclic voltammetry in order to validate their electrochemical behavior and to analyze their potentialities towards single cell analysis. Figure 5 shows the voltammetric responses at different scan rates (from 5 to $200 \mathrm{mV} / \mathrm{s}$ ) of a recessed ring nanoelectrode in aqueous solution containing $1 \mathrm{mM}$ $\mathrm{Fc}(\mathrm{MeOH})$ and $0.1 \mathrm{M} \mathrm{KCl}$. In agreement with theory and previous results of voltammetry at RNE nanodevices, voltammograms demonstrate a steady-state sigmoidal response and display slight hysteresis on the reverse scan (especially for lower scan rates). Surprisingly, the limiting currents were found to depend on the scan rate, ranging between 660 and $820 \mathrm{pA}$. This phenomenon is not clearly elucidated up to now.

In the literature, few studied have been devoted to ring microelectrode compared to disk microelectrode that attracts wide attention. To the best of our knowledge, no theoretical investigation has been performed to study the diffusion process at recessed ring nanoelectrode. Therefore, from Szabo works [6], we have developed a mathematical model that describes the expression of the limiting current $\mathrm{i}_{\lim }$ at the stationary domain: 


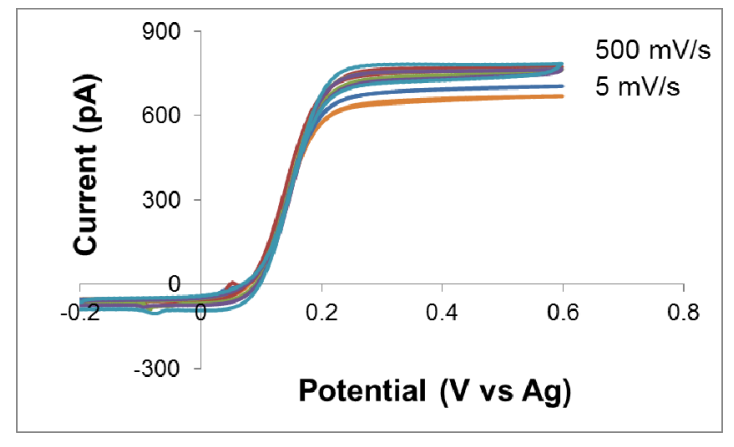

Figure 5: Cyclic voltammograms obtained with the platinum ring nanoelectrodes in $1 \mathrm{mM} \mathrm{Fc(MeOH)} \mathrm{solution}$ at different scan rates

with:

$$
\mathrm{i}_{\lim }=\frac{\mathrm{nFDC}{ }^{*} 1_{0}}{1+\frac{4 \mathrm{H}}{\pi \mathrm{b}}}
$$

$$
1_{0}=\frac{\pi^{2}(\mathrm{a}+\mathrm{b})}{\ln \left(\frac{32 \mathrm{a}}{\mathrm{b}-\mathrm{a}}+\exp \left(\frac{\pi^{2}}{4}\right)\right)}
$$

where $\mathrm{n}$ is the number of electrons transferred, $\mathrm{F}$ is the Faraday constant, D is the diffusion coefficient, $\mathrm{C}$ is the bulk concentration, $\mathrm{H}$ is the recessed depth, $\mathrm{a}$ and $\mathrm{b}$ are the ring inner and outer radius respectively (Fig. 6).

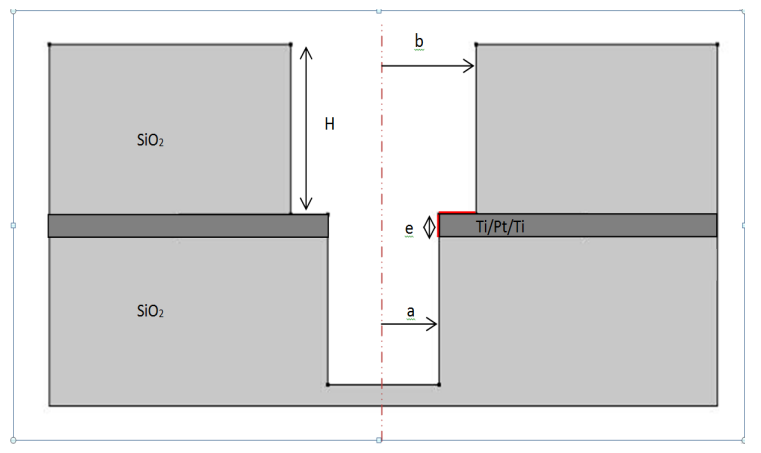

Figure 6: Theoretic configurations of recessed ring nanoelectrodes integrated into microwells

According to our experimental values and to equations (1) and (2), a limiting current in the $[650-690 \mathrm{pA}]$ range was estimated. Compared to the experimental range obtained previously (Fig. 5), the agreement is globally good, validating our theoretical model.

\section{Electrochemical investigations of recessed ring nanoelectrode arrays}

The scan rate studies were performed for $10 \times 10 \mathrm{RNE}$ arrays by measuring voltammetric responses for different $\mathrm{d} / \mathrm{a}$ ratios and scan rates varying between 5 and $500 \mathrm{mV} / \mathrm{s}(\mathrm{d}$ is the center to center distance between neighboring microwell and a is the microwell inner radius). Thus, we should provide experimentally the necessary $d$ that is large enough to allow the development of hemispherical diffusion layers over the individual microelectrodes in the array. Cyclic voltammograms (CV) of the recessed RNE arrays in $1 \mathrm{mM} \mathrm{Fc}(\mathrm{MeOH})$ were shown in figure 7. It can be seen that when d equals 5a (Fig. 7a), the response of the RNE arrays loses the steady state characteristic, indicating consequent overlapping of individual diffusion layers of the adjacent microelectrodes and the development of planar diffusion. In this case, mass transport to the electrodes was reduced and measured current was lower in comparison to its theoretical values. Upon increasing $\mathrm{d} / \mathrm{a}$, current responses switch between planar and hemispherical diffusion. When the RNE were well separated (d upper to 15a) (Fig. 7b), steady state behavior was obtained when scan rate was varied between 50 to $500 \mathrm{mV} / \mathrm{s}$.
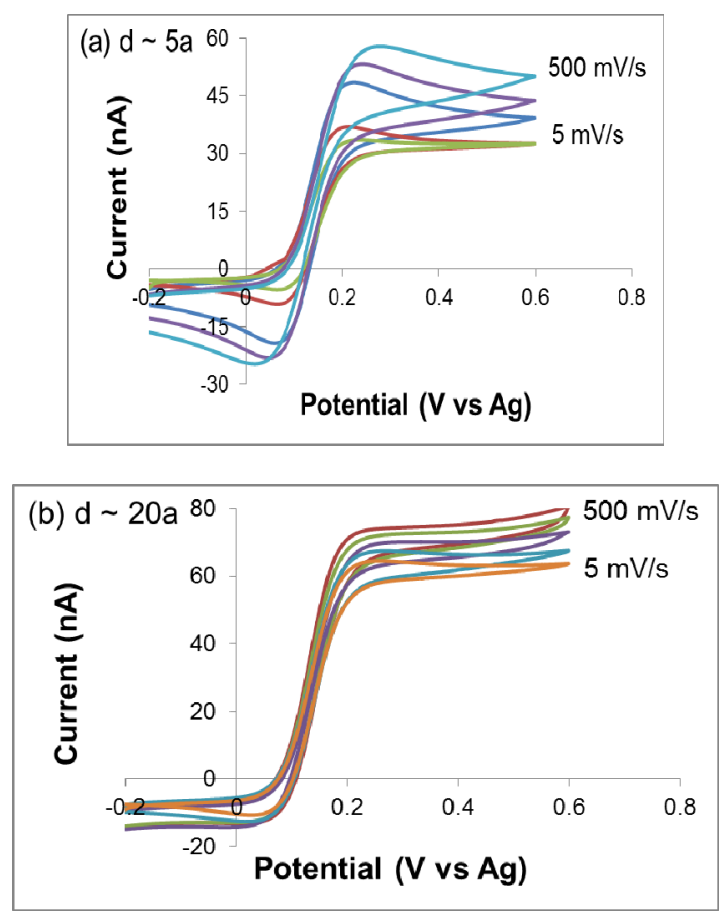

Figure 7: Cyclic voltammograms obtained in $1 \mathrm{mM}$ $\mathrm{Fc}(\mathrm{MeOH})$ solution on platinum-based RNE-arrays with different inter-electrodes distances at various scan rates: (a): $d=5 a$, (b) $d=20 a$.

As we decrease the scan rate, the timescale of the experiment increases resulting in larger diffusion zones and a decrease in the magnitude of the current. On the other hand, if we increase scan rate, we shorten the timescale of the experiment resulting in smaller diffusion zones. Thus, we can usually avoid overlapping and move from planar to hemispherical diffusion by simply increasing the scan rate. From Fig.7 results, a clear conclusion is that a center-to- 
center distance of 20a was more suitable in order to avoid diffusion layers overlapping and allow steady state characteristics develop even at lower scan rates. This design rule should be retained for future technological realization and has been kept for the following results.

\section{Electrochemical characterization in generator-collector mode}

In order to check the confinement effects of microcavities on the amperometric responses, we investigate the electrochemical behavior of RNE arrays $(d=20 a)$ in generator/collector working mode. The confined volume of solution over the electrode array prevents escape of redox species, and lateral diffusion.

Microwells used in these studies contain recessed disk (DME) microelectrodes at their bottom and recessed nanoring electrodes (RNE) at its mid-depth. In the present experiment, the disk microelectrode was held at an anodic potential $(\mathrm{E}=0.4 \mathrm{~V}$ versus $\mathrm{Ag}$ ) in order to oxidize ferrocene (Fc) to ferrocenium $\left(\mathrm{Fc}^{+}\right)$. Then, this specie was reduced on the ring nanoelectrodes held at a cathodic potential $(\mathrm{E}=0 \mathrm{~V}$ versus Ag). Finally, the regenerated Fc specie can diffuse back to the disk electrodes for re-oxidation. Typical chronoamperometric curves obtained for disk microelectrode and ring nanoelectrode were presented on figure 8 . In both cases, steady-state responses were clearly evidenced, allowing to measure the limiting current. First, the DME limiting current values were compared for RNE nanodevices polarized or not. Thus, an amplification factor of 1.3 was calculated to characterize the generator-collector mode. Then, the ratio between RNE and DME limiting current yielded a collection factor around 0.67 .

In the case of single cell analysis, assuming that there is no regeneration phenomenon, the effective collection factor will be the product of the amplification and collection factors, roughly equal to 0.87 . Such result was confirmed by COMSOL ${ }^{\mathrm{TM}}$ simulation while considering a constant "cellular" flux at the microwell bottom (result not shown).

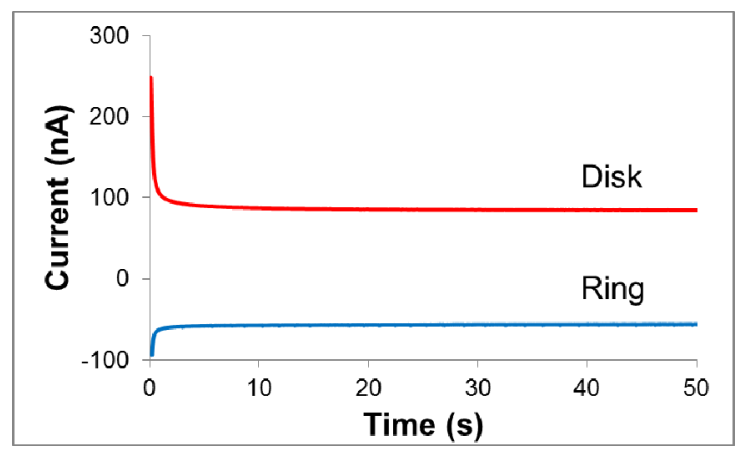

Figure 8: Chrono-amperograms for recessed disk/ring electrodes arrays $(d \sim 20 a)$ in $1 \mathrm{mMFc}(\mathrm{MeOH})$ solution (disk and ring electrodes were held at $0.4 \mathrm{~V}$ and $0 \mathrm{~V}$ respectively).

\section{CONCLUSION}

All in all, microwell arrays with platinum-based, recessed ring nanoelectrodes (RNE) were successfully integrated, studied and optimized for the electrochemical analysis in sub-picoliter volumes $(\sim 0.3 \mathrm{pL})$. Thanks to electrochemical characterizations, RNE amperometric behavior was determined and design rules were optimized for avoiding any diffusion layers overlapping from one microwell to another. Finally, the effective electrochemical factor of RNE nanodevices recessed at mid-depth of $\sim 5.2 \mu \mathrm{m}$-deep microwell was estimated around 0.87. All these results demonstrate that recessed ring nanoelectrode arrays are fitted with the statistic analysis of single cells and to the detection of related chemical species at the nanoscale.

\section{ACKNOWLEDGEMENTS}

The authors would like to thank the French "Agence Nationale de la Recherche" (project NANOMITO, n ${ }^{\circ} \mathrm{ANR}$ 2011BSV502501) for financial support. Finally, microfabrication procedure was partly supported by the French RENATECH network.

\section{REFERENCES:}

[1] C. Amatore, S. Arbault, C. Bouton, K. Coffi, J.C. Drapier, H. Ghandour and Y. Tong, "Monitoring in real time with a microelectrode the release of reactive oxygen and nitrogen species by a single macrophage stimulated its membrane mechanical depolarization", ChemBioChem, vol. 7, pp. 653-661, 2006.

[2] Y. Date, S. Takano, H. Shiku, K. Ino, T. Ito-Sazaki, M. Yokoo, H. Abe and T. Matsue, "Monitoring oxygen consumption of single mouse embryos using an integrated electrochemical microdevice", Biosensors and Bioelectronics, vol. 30, pp. 100-106, 2011.

[3] Z.P. Aguilar, W.R. Vandaveer and I. Fritsch, "Selfcontained microelectrochemical immunoassay for small volumes using mouse IgG as a model system", Analytical Chemistry, vol. 74, pp. 3321-3329, 2002.

[4] C. Ma, N.M. Contento, L.R. Gibson, P.W. Bohn, "Redox cycling in nanoscale-recessed ring disk electrode arrays for enhanced electrochemical sensitivity", ACS Nano, vol. 7, pp. 5483-5490, 2013.

[5] A. Matsutani, M. Hayashi, Y. Morii, K. Nishioka, T. Isonbe, A. Nakajima and S. Matsushita, "SF${ }_{6}$-based deep reactive ion etching of (001) rutile $\mathrm{TiO}_{2}$ substrate for photonic crystal structure with wide complete photonic band gap", Japanese Journal of Applied Physics, vol. 5, pp. 098002/1-098002/2, 2012.

[6] A. Szabo, "Theory of the current at microelectrodes: application to ring electrodes", Journal of Physical Chemistry, vol. 91, pp. 3108-3111, 1987.

\section{CONTACT}

*Pierre Temple-Boyer, Tel: +33 561336 954; temple@laas.fr 